\title{
Psychological Changes and Cancer Occurrence of Citizens due to Changes in Concentration before Seoul Fine Dust Policy
}

\author{
Kilyong Choi ${ }^{1}$ and Wonho Yang ${ }^{2 *}$ \\ 1 Department of Environmental Energy Engineering, Anyang University, 14028, South Korea; bestchoi94@an- \\ yang.ac.kr \\ 2 Department of Occupational Health, Daegu Catholic University, 38430, South Korea \\ * Correspondence: whyang@cu.ac.kr; Tel: +82-53-850-3739; Fax: +82-53-850-3736
}

\begin{abstract}
Background: Particulate matter and urban air pollution affect the human body and can lead to death. Epidemiological studies should consider the exposure to pollutants and the diverse responses of individuals depending on their sensitivity to the pollutants. Methods: In this study, air pollution measurements were obtained hourly at measuring stations operated by the national and local governments to increase the reliability of the measured values. A $\beta$-ray absorption method was used to analyze the measurements of fine dust and determine the particulate matter content. Results: The air pollution data were log-value to enable the comparison of data from different time periods. The comparison was made, focusing on the period of Seoul's fine dust policy. As a result, the cancer incidence rate also decreased after the policy. The data on individual characteristics were obtained from a survey of Seoul citizens conducted from 2015 to 2016 and using indicators such as the quality of life and social trust of Seoul citizens. Concludions: The survey on the living environment and residence indicated that $80 \%$ of the heads of households were men. Women had a greater dissatisfaction than men with the residential, economic, and social environments. The survey questions on well-being were related to the internal and external environment such as air pollution, noise, and fine dust.
\end{abstract}

Keywords: Environmental diseases; Air pollution; Fine dust; Living environment; Satisfaction; Policy

\section{Introduction}

In recent years, a number of studies have been published on various respiratory symptoms caused by air pollution and the associated psychological and physiological evaluation of the affected individuals [1,2]. The human body is greatly influenced by the environment and various studies have been conducted to determine methods to prevent exposure to various environmental factors in the atmosphere as a result of environmental changes. Particulate matter (PM) and urban air pollution affect the human body and can lead to death [3-6]. The concentration of PM (coarse PM (PM10), fine PM (PM2.5)) in the atmosphere has been investigated in relation to respiratory and cardiovascular diseases and correlations between these diseases and the presence of fine dust have been reported $[7,8]$. Epidemiological studies on air pollution should consider the exposure to pollutants and the diverse responses of individuals depending on their sensitivity to the pollutants. Air pollution is very sensitive to temperature and meteorological changes and studies should take into account the changes in these factors and their impact on the results [9]. Seasonal changes in air pollution, regional characteristics, and population distribution are considered important variables, not only in Korea but also worldwide [10]. Climate change has a direct effect on the length and timing of the seasons. The prevention of the adverse health effects of environmental pollutants is required to address problems such as diseases and mortality [11]. Studies have provided evidence that the fear of exposure to various air pollutants can cause psychological effects; these studies focused on the analysis of air pollution factors affecting seasonal disease occurrence and the treatment of the 
diseases [12, 13]. In addition, health concerns about air pollution are changing people's attitudes towards outdoor activities, causing confusion, increasing distrust in society and the state, and causing ideological conflict.

For the purpose of research, the Seoul Metropolitan Government has been implementing the policy process for the fine dust season system since 2015. I want to check the impact. There are some data on atmospheric exposure and health indicators, but there is no study confirming the correlation between recent abnormal symptoms and health anxiety factors. This study is based on the hypothesis that the correlation of PM10 and PM2.5 concentrations in Seoul, Gyeonggi, and Incheon varies seasonally. The data indicate that the population in the residential areas in Seoul is directly affected by air pollution, noise, lack of greenery, and water pollution.

\section{Materials and methods}

\subsection{Survey}

A survey of Seoul citizens was conducted from 2015 to 2016 using 227 indicators (12 areas, 42 items) of the quality of life, social trust, and community consciousness. The survey included questions regarding the satisfaction with the living environment. According to the 2016 data, the score for the satisfaction with the residential environment (water supply and sewage, housing, telecommunication, traffic, green areas, etc.) was highest (6.16 points out of 10 points), the satisfaction with the social environment (welfare, disease, medical facilities, etc.) was 5.71 points, the satisfaction with the educational environment was 5.43 points, and the satisfaction with the economic environment was 5.31 points. The satisfaction based on gender was determined. The highest score was observed for the residential environment and was influenced by the factors of waterworks, sewage, housing, electricity, communication, traffic, and greenery. In the category of daily life concerns, problems related to parking had the highest proportion (49.1\%), followed by street litter $(40.4 \%)$, crime and violence (32.8\%), and air pollution (32.3\%). The low values for air pollution and water quality issues are important considering the immediate and future impacts of fine dust.

\subsection{Air Pollution Data}

Airborne pollution data were obtained hourly from national and local government measuring stations. The average annual concentration (less than $50 \mu \mathrm{g} / \mathrm{m}^{3}$ ) and the average daily concentration (less than $100 \mu \mathrm{g} / \mathrm{m}^{3}$ ) of fine dust (PM10 and PM2.5) were measured using the $\beta$-ray absorption method. This method captures PM of $10 \mu \mathrm{m}$ or less in the air (the particle size can be controlled according to the separation device). The sample is placed on filter paper for a certain period of time, permeates the betaine. The weight concentration of the PM is measured continuously. This measurement method determines the $\beta$-radiation absorbed by the dust particles on the filter paper. The analysis was conducted based on the following formula:

I = Io ing fo $\mu$ X)

I: $\beta$-ray intensity transmitted through the dust on the filter paper

Io: $\beta$-ray intensity transmitted through a blank filter paper

$\mu$ : Absorption coefficient of $\beta$-ray absorption by dust $(\mathrm{cm} 3 / \mathrm{mg})$

$\mathrm{X}$ : Mass of the collected basin per unit area $(\mathrm{mg} / \mathrm{cm} 3)$

Therefore, the dust concentration is determined by the amount of the absorption of the beta rays by the mass of the dust collected per unit area. The dust concentration is determined by:

$C=(S / \mu \times V \times \Delta t) \operatorname{In}(I / I o)$

C: Dust concentration $(\mathrm{mg} / \mathrm{m} 3)$

$\mathrm{S}$; Area of filter paper $\left(\mathrm{cm}^{2}\right)$

V: Amount of air absorbed $\left(\mathrm{m}^{3}\right)$

$\triangle \mathrm{t}$; Collection time (min) 


\subsection{Statistic}

The data analysis was performed using the statistical software SAS version 9.4 (SAS Institute Inc., Cary, NC, USA). We analyzed parameters for life satisfaction (living environment, economic environment, and social environment) and levels of well-being (noise, air pollution, rest spaces, lack of greenery, and water pollution). Gender differences were analyzed. A logistic regression model was used to compare the seasonal changes and regional characteristics of the PM10 and PM2.5 concentrations near the homes of the subjects. A 95\% confidence interval (CI) and probability ratios (odds ratios (ORs)) were used to determine significant differences. A p-value $<0.05$ was considered statistically significant. The dependent variables were the individual characteristics and the local dust (PM10, PM2.5) concentrations. The independent variables were divided into categories representing gender and changes in summer.

\subsection{Diagnostic Code Analysis of Cancer Registration Data}

The sample of this study is a cohort of Seoul residents, Incheon, and Gyeonggi-do, and it is difficult to identify and epidemiologically approach the short-term. As a result of the cohort. In terms of policy application and management due to the characteristics of Seoul, the purpose of the protocol according to accumulation observation as the cause of disease according to the outcome was defined as follows. The customized DB confirmed the health insurance claim data (qualification, treatment DB) of all persons with a residence code from 2009 to 2019. The cohort type was an open cohort according to the residential area by year after the start of follow-up (2009). This study analyzed 15 cancers (All Cancers(C00-C96), lung Cancer(C33-C34), Stomach Cancer(C16), liver Cancer(C22), Colorectal Cancer(C18-C20), Breast Cancer(C50), Cervical Cancer(C53), Cancer of the esophagus(C15), gallbladder cancer(C23-C241), pancreatic cancer(C25), laryngeal Cancer(C32), Small intestine cancer(C17), Skin cancer(C44), Renal cancer(C64-C68), Leukemia(C91C95), Thyroid Cancer(C73)) that were found to be induced in the environment among the representative cancers (24 types) in Korea.

\section{Results}

\subsection{Living Environment and Residence}

Table 1 results are related to the living environment of the survey subjects. First, in the survey of heads of households, males accounted for about $80 \%$ of survey subjects during 2015 to 2016, a much higher proportion than females. According to the income characteristics of Seoul, 40 million won was about $30 \%$ in 15 years. In households with an income of more than 5 million KRW, the ratio of the income to the income of over 5 million was higher than in other years, followed by the income of people with 15 years and 16 years of education. An education of more than 16 years was not investigated and has 15 years. It is confirmed that the survey respondents in Seoul have high education and high income. 
Table 1. Gender, income, and education levels of survey respondents in Seoul.

\begin{tabular}{|c|c|c|c|c|c|c|}
\hline \multirow[b]{2}{*}{ Gender } & \multicolumn{2}{|c|}{$\begin{array}{l}\text { Questionnaire for } 2016 \\
\text { (head of household) }\end{array}$} & \multicolumn{2}{|c|}{$\begin{array}{l}\text { Questionnaire for } 2015 \\
\text { (head of household) }\end{array}$} & \multicolumn{2}{|c|}{$\begin{array}{l}\text { Questionnaire for } 2014 \\
\text { (head of household) }\end{array}$} \\
\hline & & P-value & & P-value & & P-value \\
\hline Men & $16626(83.1)$ & & $17326(86.6)$ & & $16931(847)$ & \\
\hline Women & 3374(169) & & 2674(134) & & $3069(153)$ & \\
\hline \multicolumn{7}{|l|}{ Income } \\
\hline $200>$ & $1876(9.4)$ & & $1273(64)$ & & 2471(124) & \\
\hline $201 \sim 400$ & $6520(326)$ & $<0001$ & $4768(238)$ & $<0001$ & $7792(39.0)$ & $<0001$ \\
\hline $401-500$ & $7322(36.6)$ & & $3418(17.1)$ & & $4532(26)$ & \\
\hline $501<$ & 4282(21.4) & & $10541(527)$ & & $5205(260)$ & \\
\hline Education & - & & & & & \\
\hline Middleschoolgraduation & - & & $1353(6.8)$ & & 2012(10.1) & \\
\hline Highschoolgraduation & - & - & $7323(36.6)$ & $<0001$ & $6551(327)$ & $<0001$ \\
\hline Universitygraduation & - & & $10983(549)$ & & $11096(55.5)$ & \\
\hline Graduateschoolgraduation & - & & $341(1.7)$ & & $341(1.7)$ & \\
\hline
\end{tabular}

Table 2 surveyed the satisfaction with the living environment (living environment, economic environment, social environment) and the well-being (noise, air pollution, resting space, water pollution, etc.). The survey data for 2015 to 2016 indicated a satisfaction with various factors related to the living environment. Life safety was significant in the data for 2015 data.

Table 2. Living environment and well-being in Seoul.

\begin{tabular}{|c|c|c|c|c|c|c|}
\hline & \multicolumn{2}{|c|}{$\begin{array}{l}\text { Questionnaire for } 2016 \text { (Households by } \\
\text { gender) }\end{array}$} & \multicolumn{2}{|c|}{$\begin{array}{l}\text { Questionnaire for } 2015 \text { (Households by } \\
\text { gender) }\end{array}$} & \multicolumn{2}{|c|}{$\begin{array}{l}\text { Questionnaire for } 2014 \text { (Households by } \\
\text { gender) }\end{array}$} \\
\hline $\begin{array}{l}\text { Lifeenvironment } \\
\text { satisfaction }\end{array}$ & *CnudeOR( $(5 \%$ Cl) & P-value & ${ }^{*}$ CrudeOR( $\left.95 \% \mathrm{Cl}\right)$ & P-value & ${ }^{*}$ CrudeOR(95\%Cl) & P-value \\
\hline Residentialenvironment* & $3.41(338,3,44)$ & $<0001+$ & $3.43(341,346)$ & 0.0164 & $3.40(338,3,43)$ & $<0001 t$ \\
\hline Economicenvironment & $3.03(3.01,3.06)$ & $<0001+$ & $3.02(299,3.05)$ & $<0001+$ & $3.02(299,305)$ & $<0001 t$ \\
\hline 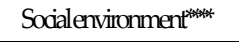 & $3245(322,327)$ & $<0001+$ & $324(321,327)$ & 0.0034 & $323(320,326)$ & $<0001+$ \\
\hline \multicolumn{7}{|l|}{ Well-being } \\
\hline Noise & $216(214,219)$ & 03872 & $218(215,220)$ & 0.6399 & $6.42(630,655)$ & $<0001+$ \\
\hline Air pollution & $220(217,22)$ & 08011 & $217(214,220)$ & 0.02267 & $372(3,53,3,90)$ & 0.03977 \\
\hline Relaxation space & $212(210,214)$ & 09974 & $214(211,216)$ & 0.1891 & $4.70(4.47,4.93)$ & 0.3714 \\
\hline Water pollution & $207(204,209)$ & 03105 & $206(203,208)$ & 0.1131 & $5.42(5.16,5.68)$ & 03106 \\
\hline
\end{tabular}

*women's Crude OR (95\% CI: confidence interval). W* Water and sewage, housing, electrical, communication, traffic, green space, etc. Living expenses, income, working hours, etc. Welfare, disease, medical facilities, etc. Relion space and lack of green space. $\Varangle p \varangle 0.05, t p \varangle 0.001$

\subsection{Outdoor environment}

The raw data from the outdoor air pollution monitoring network were compared with the log-value data. Table 3, 4, 5 results are based on the analysis of the fine dust, which is one of the variables affecting the living environment. In 2015, the PM10 concentrations for Gyeonggi and Incheon were $3.73 \mu \mathrm{g} / \mathrm{m}^{3}$ and the PM2.5 concentration was 3.24 $\mu \mathrm{g} / \mathrm{m}^{3}$ in Incheon and $3.04 \mu \mathrm{g} / \mathrm{m}^{3}$ in Gyeonggi; the PM2.5 concentration was low in Seoul $\left(2.91 \mu \mathrm{g} / \mathrm{m}^{3}\right)$. 
Table 3. Concentration (log-value) of fine dust (PM10, PM2.5) in Seoul, Incheon, and Gyeonggi.

\begin{tabular}{|c|c|c|c|c|c|c|c|c|c|c|c|c|}
\hline & \multicolumn{4}{|c|}{ Fine dust concentration in $2016\left(\mu \mathrm{g} / \mathrm{m}^{3}\right)$} & \multicolumn{4}{|c|}{ Fine dust concentration in $2015\left(\mu \mathrm{g} / \mathrm{m}^{3}\right)$} & \multicolumn{4}{|c|}{ Fine dust concentration in $2014\left(\mu \mathrm{g} / \mathrm{m}^{3}\right)$} \\
\hline $\begin{array}{c}\text { Area and } \\
\text { measure } \\
\text { ment } \\
\text { target }\end{array}$ & $\mathbf{N}$ & minimum & maximum & average & $\mathbf{N}$ & minimum & maximum & average & $\mathrm{N}$ & minimum & maximum & average \\
\hline SeoulPMio & 332331 & 0 & 629 & 3.76 & 27046 & 0 & 694 & 3.63 & 339171 & 0 & 5.7 & 3.67 \\
\hline SeoulPMbs & 212000 & 0 & 5.1 & 3.08 & 18195 & 0 & 5 & 291 & - & - & - & - \\
\hline IndheonPMio & 176097 & 0 & 687 & 3.73 & 24328 & 0 & 686 & 3.73 & 172484 & 0 & 5.75 & 3.74 \\
\hline Indheon $\mathrm{PM}_{25}$ & 119060 & 0 & 5.41 & 3.02 & 7771 & 0 & 5.06 & 324 & - & - & - & - \\
\hline $\begin{array}{c}\text { Gyeonggi } \\
\text { PMio }\end{array}$ & 686650 & 0 & 6.6 & 3.8 & 24549 & 1.1 & 673 & 3.73 & 676932 & 0 & 699 & 38 \\
\hline $\begin{array}{c}\text { Gyeongi } \\
\mathrm{PM}_{25}\end{array}$ & 218809 & 0 & 5.48 & 3.11 & 11155 & 0 & 5.16 & 3.04 & - & - & - & - \\
\hline
\end{tabular}

Table 4. Seasonal and average fine dust (PM10, PM2.5) concentrations (log-value).

\begin{tabular}{|c|c|c|c|c|c|c|c|c|c|c|}
\hline \multirow{3}{*}{$\begin{array}{c}\text { Areaand } \\
\text { measurement } \\
\text { target }\end{array}$} & \multicolumn{4}{|c|}{ Fine dust concentration in $2016\left(\mu \mathrm{g} / \mathrm{m}^{3}\right)$} & \multicolumn{3}{|c|}{ Fine dust concentration in $2015\left(\mu \mathrm{g} / \mathrm{m}^{3}\right)$} & \multicolumn{3}{|c|}{ Fine dust concentration in $2014\left(\mu \mathrm{g} / \mathrm{m}^{3}\right)$} \\
\hline & \multirow[b]{2}{*}{ season } & \multicolumn{2}{|c|}{ Averageconcentration } & \multirow[b]{2}{*}{ P-value } & \multicolumn{2}{|c|}{ Averageconcentration } & \multirow[b]{2}{*}{ P-value } & \multicolumn{2}{|c|}{ Averageconcentration } & \multirow[b]{2}{*}{ P-value } \\
\hline & & $\begin{array}{c}\text { NHow } \\
(\%)\end{array}$ & $\begin{array}{c}\text { N=High } \\
(\%)\end{array}$ & & $\begin{array}{l}\text { NLow } \\
(\%)\end{array}$ & $\begin{array}{c}\text { NHigh } \\
(\%)\end{array}$ & & $\begin{array}{c}\text { N-Low } \\
(\%)\end{array}$ & $\begin{array}{c}\mathrm{NH} \text { High } \\
(\%)\end{array}$ & \\
\hline \multirow{4}{*}{ SeoulPMin } & Summer & $54316(33.1)$ & $28829(17.1)$ & \multirow{4}{*}{$<0001+$} & $4826(353)$ & 1697(127) & \multirow{4}{*}{$<0001+$} & $54924(327)$ & $31544(184)$ & \multirow{4}{*}{$<0001+$} \\
\hline & autumn & $45731(27.9)$ & $35641(212)$ & & $4174(305)$ & 1996(149) & & $52598(313)$ & $31561(184)$ & \\
\hline & Winter & 39321(24) & $44104(262)$ & & $2571(188)$ & $5212(39.0)$ & & $35719(213)$ & $46474(27.1)$ & \\
\hline & Spring & 24574(15) & $59815(35.5)$ & & $2104(154)$ & $4466(33.4)$ & & $24604(147)$ & $61747(36.0)$ & \\
\hline \multirow{4}{*}{ SeoulPMb5 } & Summer & $28731(272)$ & $24476(23)$ & \multirow{4}{*}{$<0001+$} & $2583(278)$ & 1612(18.1) & \multirow{4}{*}{$<0001+$} & & \multirow{4}{*}{$\mathrm{ND}$} & \\
\hline & Autumn & $28086(26.6)$ & $23326(21.9)$ & & $2714(292)$ & $1408(158)$ & & & & \\
\hline & winter & 26511(25.1) & $26930(253)$ & & $1935(20.8)$ & $3644(41.0)$ & & & & \\
\hline & Spring & $22346(21.1)$ & $31664(29.8)$ & & $2072(223)$ & $222(25.1)$ & & & & \\
\hline \multirow{4}{*}{ IndheonPMio } & Summer & $28290(326)$ & 16071(18.0) & \multirow{4}{*}{$<0001+$} & $3733(30.4)$ & 1835(153) & \multirow{4}{*}{$<0001+$} & $26236(302)$ & 15839(185) & \multirow{4}{*}{$<0001+$} \\
\hline & Autumn & $22994(26.5)$ & $21535(242)$ & & $2828(23)$ & 1657(138) & & $26039(30.0)$ & $18803(220)$ & \\
\hline & Winter & $22641(26.1)$ & $20655(23.0)$ & & $3277(26.6)$ & $4416(367)$ & & $20766(23.9)$ & $21367(25.0)$ & \\
\hline & Spring & 12985(14.9) & $31026(34.8)$ & & $2459(20)$ & $4123(343)$ & & $13900(16.0)$ & $29534(345)$ & \\
\hline \multirow{4}{*}{ Indheon $\mathrm{PM}_{25}$} & Summer & 18873(321) & $12473(20.7)$ & \multirow{4}{*}{$<0001+$} & 991(252) & $1034(27.0)$ & \multirow{4}{*}{$<0001+$} & & \multirow{4}{*}{$\mathrm{ND}$} & \\
\hline & Autumn & $17889(29.4)$ & $17155(28.4)$ & & $1244(31.6)$ & 88123) & & & & \\
\hline & Winter & $11635(19.8)$ & $12644(21.0)$ & & $1065(27.0)$ & $1064(278)$ & & & & \\
\hline & Spring & 10997(18.7) & $17994(29.9)$ & & $640(162)$ & $852(22)$ & & & & \\
\hline \multirow{4}{*}{ GyeonggiPMn } & Summer & $124278(36.0)$ & 46156(13.5) & \multirow{4}{*}{$<0001+$} & $3303(26.6)$ & 1332(11.0) & \multirow{4}{*}{$<0001+$} & 107465(321) & $63758(18.7)$ & \\
\hline & Autumn & 91757(26.6) & 76913(225) & & $3318(267)$ & $209(182)$ & & $104968(313)$ & 62470(183) & $<\mathrm{mm}+$ \\
\hline & Winter & $7585(22)$ & $97315(285)$ & & $2912(235)$ & $4848(39.9)$ & & $72127(215)$ & $92844(72)$ & 80011 \\
\hline & Spring & $53044(15.4)$ & $121312(355)$ & & 2878(232) & $3749(30.9)$ & & $50451(15.1)$ & $122849(35.9)$ & \\
\hline & summer & $34513(31.0)$ & $20402(19)$ & & $1206(221)$ & 717(126) & & & & \\
\hline GreonooipMb & Autumn & $36525(328)$ & $32101(299)$ & $<000 t$ & $1722(31.6)$ & 1079(189) & $<0001$ & & $\mathrm{ND}$ & \\
\hline & Winter & $20707(18.6)$ & $27826(259)$ & & $1532(28.1)$ & $2712(475)$ & & & & \\
\hline & spring & $19699(17.7)$ & $27036(252)$ & & 991(182) & $1196(21.0)$ & & & & \\
\hline
\end{tabular}


Table 5. Correlation (OR) between the concentration of the average fine dust (PM10, PM2.5) and the season (log-value).

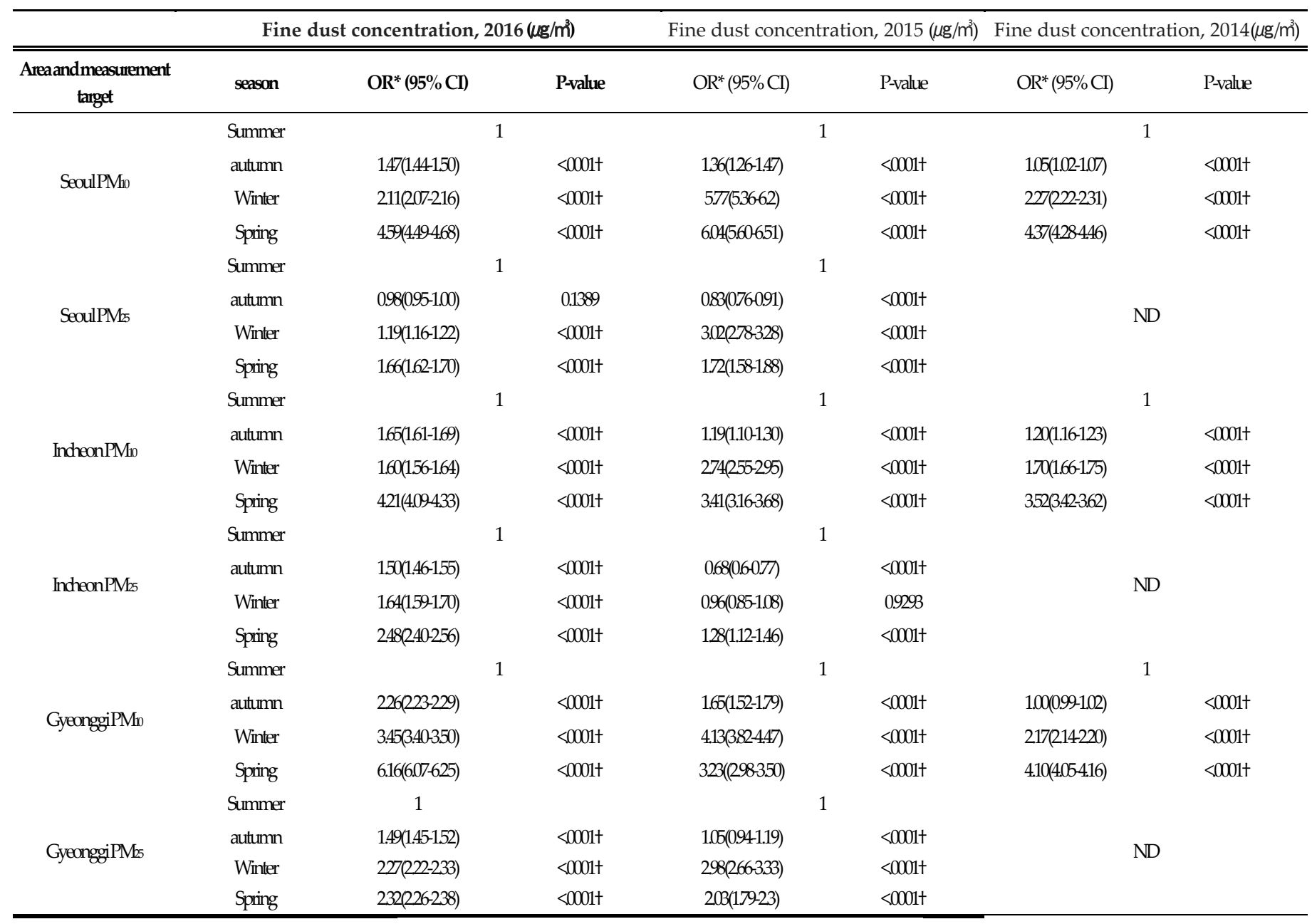

*Odds Ratio 95\% Confidence Limits; $\ddagger \mathrm{p}<0.05,+\mathrm{p}<0.001$.

As shown in Tables 4 and 5, the concentration of fine dust in the Seoul area tends to be higher in the fall, winter, and spring than in the summer. This is consistent with the results of other studies. The ORs of the seasonal average PM10 concentration in 2016 are 1.47 in autumn, 2.11 times in winter, and 4.59 in spring. In Incheon, the ORs are 1.65 in the autumn, 1.60 in the winter, and 4.21 times in the spring. The Gyeonggi area showed a trend of increasing seasonal fine dust concentrations (2.26 in the autumn, 3.45 in the spring, and 6.16 in the spring). The values were statistically significant $(P$-value $<.0001)$ for the fall of 2016. The OR for PM2.5 was 0.98 (statistically insignificant) and increased to 1.19 in the winter and 1.66 in the spring (1.50, 1.64, and 2.48 in Incheon). The OR values for PM10 for Gyeonggi were 1.49, 2.27, and 2.32 and were lower than the values for PM10 but were statistically significant (P-value: <.0001). In 2015, the OR values for PM10 in the autumn, winter, and spring in Seoul were 1.36, 5.77, and 6.04. In Incheon, the autumn, winter, and spring values were 1.19, 2.74, and 3.41. In Gyeonggi, the autumn, winter, and spring values were $1.65,4.13$, and 3.23 . 


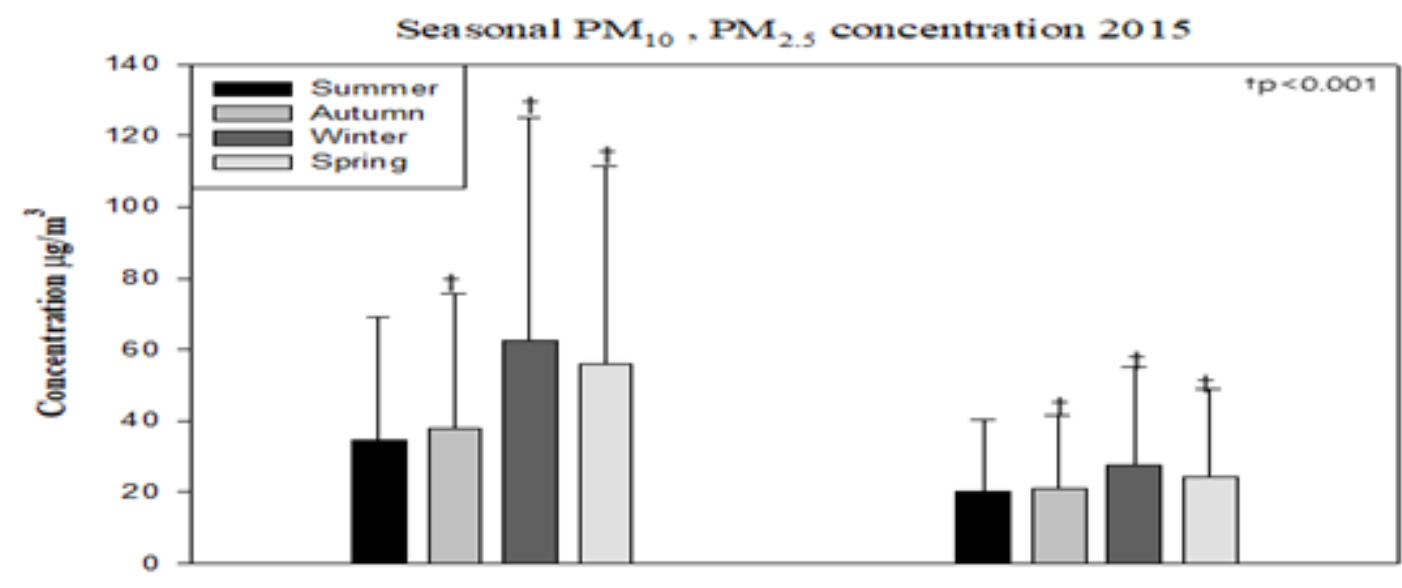

Figure 1. Correlation between the concentration (log-value) of seasonal fine dust (PM10, PM2.5) and the Seoul area (2015).

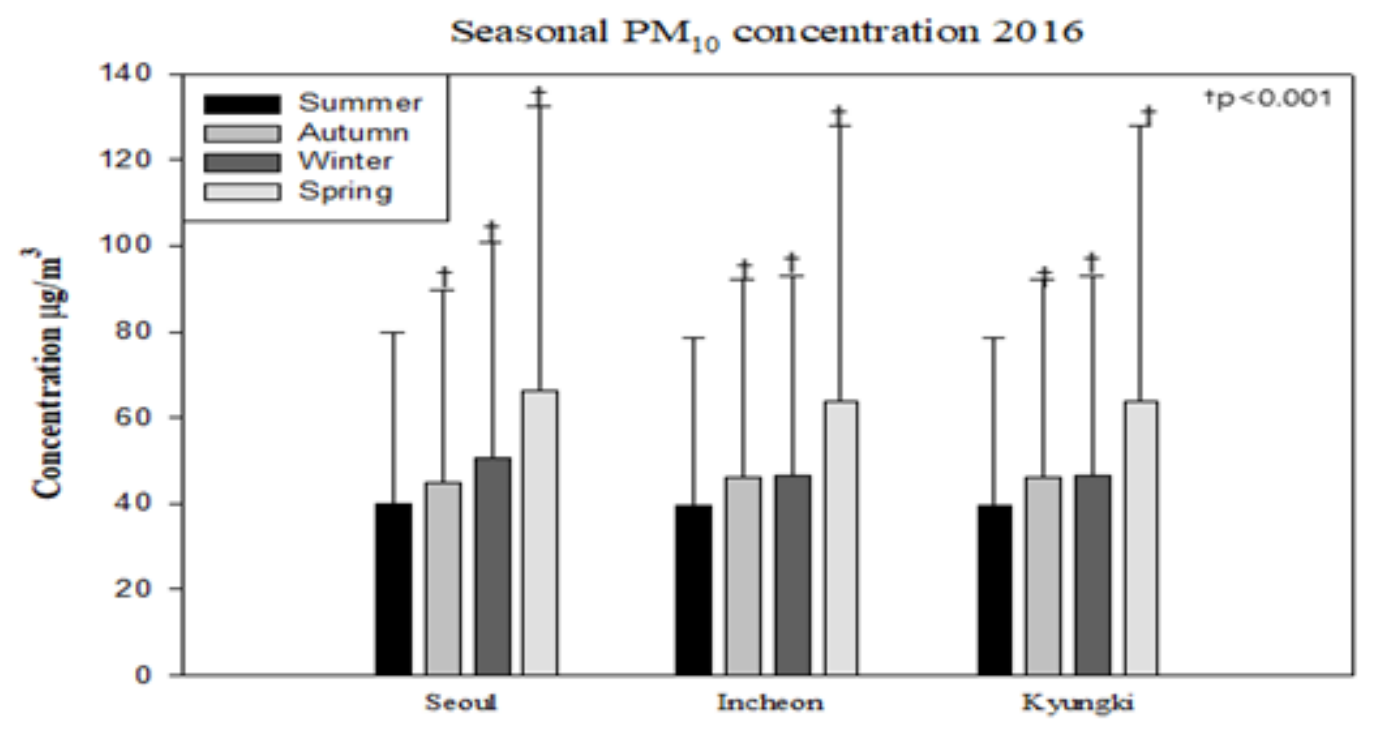

Figure 2. Correlation between the concentration (log-value) of seasonal fine dust (PM10) and the area (2016). 


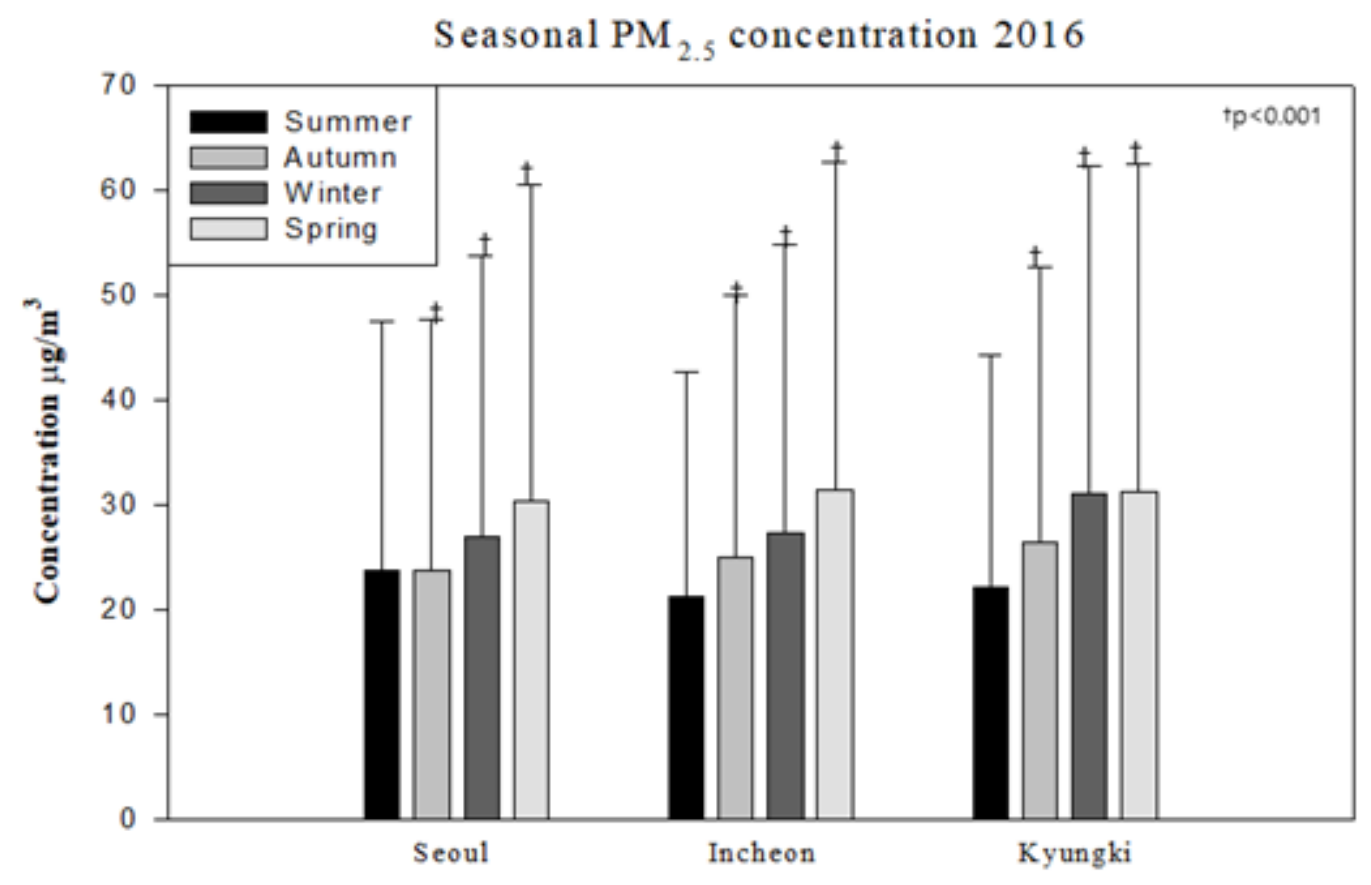

Figure 3. Relationship between the concentration (log-value) of the seasonal fine dust (PM2.5) and the area (2016).

As a result of the environmental data centered on the above data, the risk of fine dusts on the characteristics of climate change and regions (Seoul Gyeonggi and Incheon) had the same tendency. And the influence of wind confirmed direct characteristics of fine dust. Wind was blowing north and west, which had a direct effect, confirming that the impact of China was influenced by Seoul and Gyeonggi Province. These results confirm the new validation of the previous studies and can be used as good data.

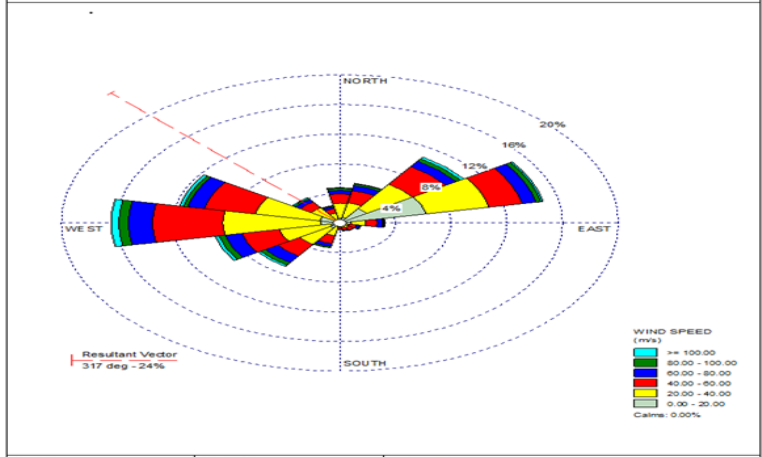

$\mathrm{PM}_{10}$ results in the target area (Seoul), 2015.

(a) PM10 results in the target area (Seoul), 2015.

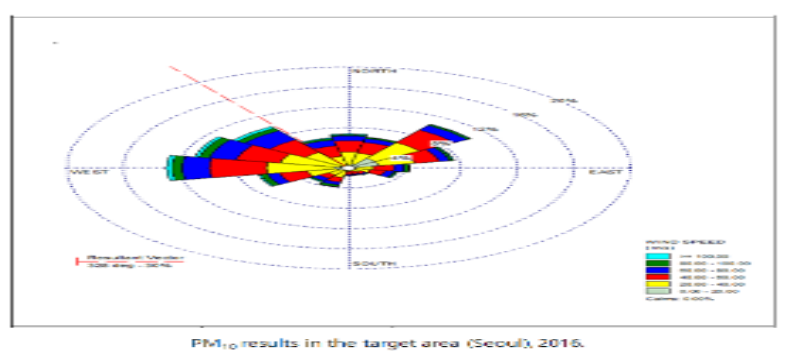

(c) PM10 results in the target area (Seoul), 2016.

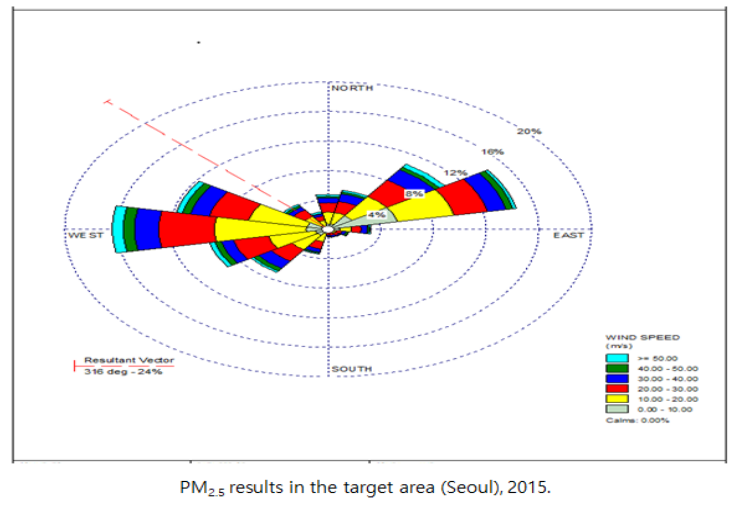

(b) PM2.5 results in the target area (Seoul), 2015.

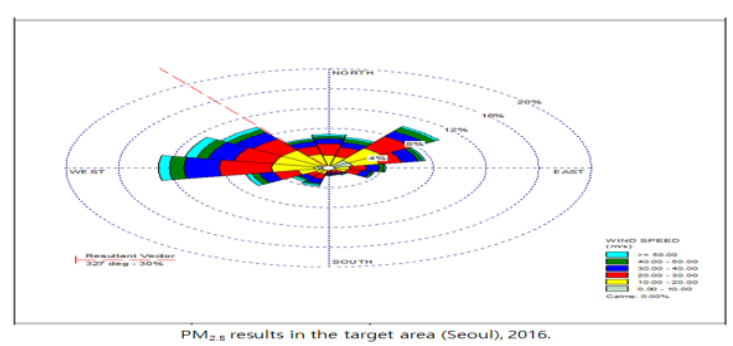

(d) PM10 results in the target area (Seoul), 2016. 
Figure 4. Correlation between the concentration (log-value) of fine dust (PM10 and PM2.5) and the local climate (wind).

In Seoul, there are many external factors for fine dust caused by Korean vehicles and external small business establishments. Accordingly, it was confirmed that the incidence of cancer was higher than Gyeonggi-do, which has many industrial complexes compared to Seoul, and Incheon, which has a high impact of fine dust and chemicals from ports. There was a statistical effect in all cancers, but it was not statistically significant in Cervical Cancer. As a result of confirming the cancer incidence rate for the seasoned policy of fine dust in urban areas, about $3 \%$ of all cancers show a continuous increase. In the first year (2019) of applying the fine dust policy, it was confirmed that the cancer incidence rate increased by $1 \%$. And in lung cancer (C33-C34), fine dust decreased after the policy (2.7\%) compared to before the policy (3.0\%). In Breast Cancer (C50), fine dust decreased after policy $(1.8 \%)$ compared to before policy $(1.9 \%)$. In laryngeal Cancer (C32), fine dust decreased after policy $(2.2 \%)$ compared to before policy $(2.8 \%)$. In Small intestine cancer (C17), fine dust decreased after policy $(1.6 \%)$ compared to before policy $(1.8 \%)$. In skin cancer (C44), fine dust decreased after policy (1.2\%) compared to before policy $(1.7 \%)$. In Thyroid Cancer (C73), fine dust decreased after policy (1.8\%) compared to before policy $(1.9 \%)$. In addition, there was no significant difference between the start of the fine dust policy (2015), which was seriously high in 2018, and the time of policy application (2019).

Table 6. Table 6. Risk ratio of major cancers according to the fine dust policy in downtown (Seoul).

\begin{tabular}{|c|c|c|c|c|c|c|c|c|c|c|c|c|}
\hline $\begin{array}{c}\text { Cancer } \\
\text { type(code } \\
\text { number) }\end{array}$ & \multicolumn{11}{|c|}{ year(number) } & \multirow[t]{2}{*}{ P-value } \\
\hline All & & & & & & & & & & & & \\
\hline $\begin{array}{c}\text { Cancers }(\mathrm{C} 00 \\
-\mathrm{C} 96) \\
\end{array}$ & 2009 & 2010 & 2011 & 2012 & 2013 & 2014 & 2015 & 2016 & 2017 & 2018 & 2019 & \\
\hline Seoul & 232,751 & 208,592 & 241,802 & 276,896 & 305,612 & 330,957 & 352,633 & 375,132 & 400,161 & 424,802 & 452,533 & - \\
\hline Incheon & 33,795 & 44,527 & 51,986 & 62,045 & 70,258 & 77,642 & 85,519 & 93,990 & 102,506 & 111,234 & 120,087 & $0.0007+$ \\
\hline $\begin{array}{l}\text { Kyungki } \\
\text { lung }\end{array}$ & 159,981 & 210,371 & 243,225 & 286,422 & 321,999 & 355,916 & 390,624 & 433,498 & 475,164 & 520,006 & 567,114 & $0.0008+$ \\
\hline \multicolumn{13}{|l|}{$\begin{array}{c}\text { Cancer(C33- } \\
\text { C34) }\end{array}$} \\
\hline Seoul & 7,292 & 5,615 & 6,635 & 8,415 & 9,393 & 10,356 & 11,300 & 12,334 & 14,195 & 16,028 & 17,872 & - \\
\hline Incheon & 1,015 & 1,174 & 1,430 & 1,943 & 2,162 & 2,381 & 2,703 & 2,976 & 3,516 & 3,994 & 4,469 & $0.0016+$ \\
\hline $\begin{array}{l}\text { Kyungki } \\
\text { Stomach }\end{array}$ & 5,040 & 6,081 & 7,158 & 9,155 & 10,285 & 11,383 & 12,637 & 14,483 & 17,247 & 19,960 & 22,648 & $0.0028+$ \\
\hline \multicolumn{13}{|l|}{ Cancer(C16) } \\
\hline Seoul & 35,321 & 26,280 & 29,893 & 33,537 & 36,202 & 38,635 & 40,572 & 42,553 & 44,862 & 46,937 & 49,125 & - \\
\hline Incheon & 5,471 & 6,345 & 7,271 & 8,495 & 9,408 & 10,247 & 11,074 & 12,014 & 12,954 & 13,863 & 14,587 & $0.0006+$ \\
\hline $\begin{array}{c}\text { Kyungki } \\
\text { liver }\end{array}$ & 24,913 & 28,556 & 32,415 & 37,223 & 40,777 & 44,356 & 47,975 & 52,409 & 56,814 & 61,123 & 65,256 & $0.0007 t$ \\
\hline \multicolumn{13}{|l|}{ Cancer(C22) } \\
\hline Seoul & 8,707 & 6,847 & 7,863 & 9,173 & 9,803 & 10,314 & 10,784 & 11,072 & 11,748 & 12,255 & 12,867 & - \\
\hline Incheon & 1,235 & 1,428 & 1,618 & 2,024 & 2,253 & 2,441 & 2,649 & 2,866 & 3,125 & 3,341 & 3,593 & $0.0008+$ \\
\hline Kyungki & 6,109 & 6,990 & 7,923 & 9,637 & 10,472 & 11,234 & 12,172 & 13,405 & 14,643 & 15,847 & 17,166 & $0.001 \dagger$ \\
\hline \multicolumn{13}{|l|}{$\begin{array}{c}\text { Cancer(C18- } \\
\text { C20) }\end{array}$} \\
\hline Seoul & 29,616 & 23,809 & 27,430 & 31,386 & 34,184 & 36,679 & 38,701 & 40,832 & 43,364 & 45,464 & 47,776 & \\
\hline Incheon & 4,338 & 5,286 & 6,172 & 7,330 & 8,169 & 8,939 & 9,838 & 10,703 & 11,680 & 12,498 & 13,331 & $0.0007+$ \\
\hline $\begin{array}{c}\text { Kyungki } \\
\text { Breast }\end{array}$ & 20,114 & 24,185 & 27,658 & 32,356 & 35,947 & 39,365 & 42,932 & 47,007 & 51,212 & 55,489 & 59,600 & $0.0007+$ \\
\hline \multicolumn{13}{|l|}{ Cancer(C50) } \\
\hline Seoul & 27,934 & 25,289 & 28,356 & 31,351 & 33,986 & 36,830 & 39,545 & 42,405 & 46,195 & 49,868 & 53,704 & - \\
\hline Incheon & 4,655 & 5,670 & 6,366 & 7,310 & 8,138 & 8,978 & 9,902 & 10,969 & 12,141 & 13,291 & 14,539 & $0.0009+$ \\
\hline Kyungki & 20,151 & 24,533 & 27,629 & 31,708 & 35,299 & 39,232 & 43,240 & 48,512 & 54,751 & 60,794 & 67,010 & $0.0013+$ \\
\hline Cervical & & & & & & & & & & & & \\
\hline \multicolumn{13}{|l|}{ Cancer(C53) } \\
\hline Seoul & 8,887 & 7,328 & 7,779 & 8,203 & 8,497 & 8,706 & 8,925 & 9,072 & 9,367 & 9,625 & 9,806 & - \\
\hline Incheon & 1,717 & 1,998 & 2,130 & 2,315 & 2,447 & 2,546 & 2,671 & 2,775 & 2,960 & 3,068 & 3,174 & 0.1067 \\
\hline Kyungki & 6,872 & 7,751 & 8,204 & 8,924 & 9,454 & 9,993 & 10,482 & 11,166 & 11,913 & 12,660 & 13,240 & 0.0689 \\
\hline \multicolumn{13}{|l|}{$\begin{array}{c}\text { Cancer of } \\
\text { the } \\
\text { esophagus( } \\
\text { C15) }\end{array}$} \\
\hline Seoul & 1,131 & 777 & 901 & 1,106 & 1,223 & 1,318 & 1,416 & 1,517 & 1,735 & 1,872 & 2,041 & - \\
\hline
\end{tabular}




\begin{tabular}{|c|c|c|c|c|c|c|c|c|c|c|c|c|}
\hline Incheon & 173 & 190 & 215 & 281 & 324 & 358 & 376 & 425 & 446 & 485 & 566 & $0.0009+$ \\
\hline Kyungki & 720 & 770 & 878 & 1,125 & 1,240 & 1,373 & 1,531 & 1,719 & 1,970 & 2,203 & 2,430 & $0.0014 \dagger$ \\
\hline \multicolumn{13}{|c|}{$\begin{array}{c}\text { gallbladder } \\
\text { cancer(C23- } \\
\text { C241) }\end{array}$} \\
\hline Seoul & 893 & 702 & 855 & 1,129 & 1,332 & 1,433 & 1,559 & 1,664 & 1,985 & 2,198 & 2,516 & - \\
\hline Incheon & 115 & 148 & 182 & 290 & 324 & 373 & 411 & 417 & 504 & 576 & 658 & $0.0013+$ \\
\hline $\begin{array}{c}\text { Kyungki } \\
\text { pancreatic } \\
\text { cancer(C25 }\end{array}$ & 558 & 689 & 851 & 1,215 & 1,411 & 1,518 & 1,681 & 2,018 & 2,371 & 2,796 & 3,120 & $0.0025+$ \\
\hline Seoul & 1,724 & 1,282 & 1,365 & 1,513 & 1,621 & 1,698 & 1,771 & 1,817 & 1,912 & 1,983 & 2,074 & - \\
\hline Incheon & 292 & 341 & 371 & 409 & 433 & 456 & 473 & 492 & 522 & 561 & 609 & $0.1118+$ \\
\hline $\begin{array}{l}\text { Kyungki } \\
\text { laryngeal }\end{array}$ & 1,223 & 1,344 & 1,455 & 1,637 & 1,771 & 1,846 & 2,001 & 2,181 & 2,299 & 2,438 & 2,551 & $0.0519+$ \\
\hline \multicolumn{13}{|c|}{ Cancer(C32) } \\
\hline Seoul & 3,177 & 2,609 & 3,209 & 3,869 & 4,403 & 5,012 & 5,601 & 6,229 & 6,960 & 7,800 & 8,543 & - \\
\hline Incheon & 545 & 646 & 786 & 962 & 1,133 & 1,285 & 1,448 & 1,642 & 1,840 & 2,100 & 2,318 & $0.0009+$ \\
\hline $\begin{array}{c}\text { Kyungki } \\
\text { Small } \\
\text { intestine } \\
\text { cancer(C17 }\end{array}$ & 2,076 & 2,663 & 3,194 & 3,896 & 4,539 & 5,293 & 6,057 & 7,091 & 8,121 & 9,300 & 10,500 & $0.0015+$ \\
\hline Seoul & 1,404 & 1,207 & 1,407 & 1,590 & 1,776 & 1,938 & 2,102 & 2,290 & 2,544 & 2,735 & 2,926 & - \\
\hline Incheon & 222 & 307 & 344 & 410 & 455 & 506 & 561 & 640 & 703 & 787 & 844 & $0.0009+$ \\
\hline $\begin{array}{l}\text { Kyungki } \\
\text { Skin }\end{array}$ & 1,050 & 1,288 & 1,457 & 1,734 & 1,913 & 2,095 & 2,341 & 2,598 & 2,983 & 3,388 & 3,668 & $0.0017 \dagger$ \\
\hline \multicolumn{13}{|l|}{ cancer(C44) } \\
\hline Seoul & 3,371 & 2,899 & 3,176 & 3,469 & 3,703 & 3,961 & 4,212 & 4,393 & 4,679 & 5,014 & 5,266 & - \\
\hline Incheon & 542 & 670 & 734 & 836 & 904 & 982 & 1,091 & 1,161 & 1,285 & 1,355 & 1,431 & $0.0006+$ \\
\hline $\begin{array}{c}\text { Kyungki } \\
\text { Renal } \\
\text { cancer(C64 } \\
\text { C68) }\end{array}$ & 2,583 & 3,100 & 3,355 & 3,775 & 4,109 & 4,468 & 4,839 & 5,306 & 5,833 & 6,312 & 6,816 & $0.0009+$ \\
\hline Seoul & 9,201 & 7,833 & 9,477 & 11,065 & 12,463 & 13,659 & 14,819 & 16,225 & 18,075 & 20,110 & 22,451 & - \\
\hline Incheon & 976 & 1,123 & 1,375 & 1,641 & 1,913 & 2,145 & 2,436 & 2,789 & 3,261 & 3,767 & 4,328 & $0.0024 \dagger$ \\
\hline Kyungki & 5,354 & 6,842 & 8,174 & 9,844 & 11,243 & 12,713 & 14,307 & 16,290 & 18,672 & 21,244 & 24,094 & $0.0016+$ \\
\hline \multicolumn{13}{|c|}{ Leukemia(C } \\
\hline \multicolumn{13}{|l|}{ 91-C95) } \\
\hline Seoul & 4,410 & 3,677 & 4,286 & 4,839 & 5,360 & 5,886 & 6,335 & 6,900 & 7,590 & 8,228 & 8,926 & - \\
\hline Incheon & 566 & 730 & 854 & 1,042 & 1,163 & 1,325 & 1,500 & 1,651 & 1,907 & 2,110 & 2,385 & $0.0011 \dagger$ \\
\hline $\begin{array}{c}\text { Kyungki } \\
\text { Thyroid }\end{array}$ & 2,876 & 3,619 & 4,165 & 4,867 & 5,519 & 6,137 & 6,875 & 7,784 & 8,884 & 10,041 & 11,234 & $0.0017 \dagger$ \\
\hline \multicolumn{13}{|c|}{ Cancer(C73) } \\
\hline Seoul & 5,917 & 4,763 & 5,368 & 6,053 & 6,532 & 6,967 & 7,350 & 7,857 & 8,449 & 9,114 & ,805 & - \\
\hline Incheon & 839 & 977 & 1,124 & 1,326 & 1,493 & 1,606 & 1,775 & 1,945 & 2,168 & 2,371 & 2,600 & $0.001 \dagger$ \\
\hline Kyungki & 3,880 & 4,567 & 5,125 & 5,911 & 6,554 & 7,229 & 7,961 & 8,686 & 9,674 & 10,642 & 11,656 & $0.0009+$ \\
\hline
\end{tabular}

$\ddagger \mathrm{p}<0.05,+\mathrm{p}<0.001$.

\section{Discussion}

Various results and indicators in a study of fine dust pollution from 2011 to 2015 were similar to the results of our study based on the economic indicators of the Seoul metropolitan area [14]. Other studies have found that monthly changes in the concentration of fine dust were related to the seasons; the concentrations increased beginning in November, peaked in February, then decreased gradually and reached the lowest level in August and September $[15,16]$. This is due to the effect of rain, wind, and weather changes in the summer, resulting in low dust concentrations. In the winter, the use of indoor and outdoor fuel increases due to heating. The polluted air does not circulate due to air congestion and the influence of air pollutants on the living environment increases. Therefore, the concentration of fine dust is higher in the winter [17]. Accordingly, the Seoul Metropolitan Government has prepared management through regulation as a process of discussing the fine dust management policy since 2015. Since then, fine dust has gradually decreased, but there has been no change in environmental diseases. Among them, according to cancerrelated information, there was a tendency to rather increase. There are three major findings of this study. In our hypothesis, we have considered various demographic, geographical, and socio-environmental factors unique to Korea, including a high excessive population density, the geographical characteristics of neighboring countries, and the presence of industrial parks in Incheon and Gyeonggi. There are few areas that are not affected by fine dust. In addition, it has been predicted that the risk of fine dust pollution in Seoul will 
increase in the coming years $[18,19]$. Second, it was confirmed that the fine dust concentration and PM content exhibited seasonal fluctuations; the PM content was lower in the summer and autumn when the precipitation was higher. These results should be taken into consideration for research studies and policy development in the future [20]. It can be confirmed that future management is necessary when looking at the decrease in environmental diseases due to policy changes, such as lung cancer and skin cancer. Finally, unlike other areas, Seoul is a densely populated area, so it will have to make efforts to achieve balanced regional development in the future. In 2019, the first fine dust policy was applied only to the operation of vehicles and large buildings. In the future, it is necessary to check various variables that contribute to population movement and balanced regional development. Therefore, it is necessary to check the effect of air pollution on the perception of the people due to the psychological impact on the living environment and the welfare of the residents in Seoul, and it is necessary to check the significant difference in the reduction of the cancer incidence.

\section{Conclusions}

The purpose of this study is to check whether seasonal changes in air pollutants according to Seoul's air policy are well managed and how much they affect health. The results of this study cannot confirm the characteristics and prevalence of all regions according to seasonal characteristics. Although there is no direct relationship between the time of the questionnaire and the results of the measurements of fine dust concentration, it is suggested that this relationship should be taken into account in future studies considering the psychological aspects and their specificity. The statistical analysis showed that the seasonal characteristics of the fine dust were significant. It will be used as important data to confirm the various changes depending on how much change in the season (season) reflects the Seoul policy and whether the extension of the policy period in the future should be considered. Previous studies have indicated that the causes for the lower concentrations of fine dust in the summer were rainfall and weather conditions (wind). These fluctuations were also observed in the neighboring areas of the Seoul metropolitan area (Gyeonggi, Incheon). The satisfaction with the living environment is very low for women with regard to the residential environment, economic environment, and social environment. Afterward, the incidence of cancer showed a decreasing trend in lung cancer, etc., in some environments after the policy. In the future, it will be necessary to check the correlation between fine dust on health and cancer and to check it in consideration of psychological factors. The accuracy of these results could be improved if accurate real-time measurements of dust concentrations and individual risk information from exposure to air pollutants were available. In addition, measures for disease management should be improved.

Author Contributions: Conceptualization, Kil Yong Choi and Won Ho Yang.; methodology, Kil Yong Choi.; software, Kil Yong Choi.; validation, Kil Yong Choi and Won Ho Yang.; formal analysis, Kil Yong Choi.; investigation, Kil Yong Choi.; resources, Won Ho Yang.; data curation, Kil Yong Choi.; writing-original draft preparation, Kil Yong Choi.; writing-review and editing, Won Ho Yang.; visualization, Kil Yong Choi.; supervision, Won Ho Yang.; project administration, Kil Yong Choi.; funding acquisition, Kil Yong Choi. All authors have read and agreed to the published version of the manuscript.

Funding: Mental Health Technology Project of the Korea Environmental Industry and Technology Institute with funding from the Ministry of Environment (grant No. 2021003320007).

Institutional Review Board Statement: We would like to suggest two researchers as possible reviewers of our paper and their names, with full contact information, are attached on a separate sheet, We would prefer that Choi, Ph.D Glover of the Environmental Health Center, Korea University Anam Hospital review our paper. While conducting policy research at Korea University Anam Hospital, this study was conducted using air pollution measurement data in Korea and data from the Clinical Cancer Information Center. In addition, it was used in "NATIONAL HEALTH INSURANCE Sharing Service" without IRB committee approval. 


\begin{abstract}
Acknowledgments: This study was conducted with the support of the Mental Health Technology Project of the Korea Environmental Industry and Technology Insti-tute with funding from the Ministry of Environment (grant No. 2021003320007).
\end{abstract}

Conflicts of Interest: The authors declare no conflict of interest.

\title{
References
}

1. Kang Choong-Min, Park Sung-Kyun, SunWoo Young, Kang Byung-Wook, Lee Hak-Sung. Respiratory Health Effects of Fine Particles (PM2.5) in Seoul. J Korean Soc for Atmos Environ. 2006;22(5):554-563.

2. Dae LJ. A Study on Indoor Air Quality in School. J Korean Soc Indoor Environ. 2010;7(2):127-134.

3. Shin Moon-Khee, Lee Choong-Dae, Ha Hyun-Sup, Choe Choon-Suck, Kim Yong-Hee. The Influence of Meteorological Factors on PM10 Concentration in Incheon. J Korean Soc Atmos Environ. 2007;23(3):322-331.

4. Lee Bo Kyoung, Kim Young Hoon, Ha Jae Yoon, Lee Dong Soo. Development of an Automated and Continuous Analysis System for PM 2.5 and Chemical Characterization of the PM 2.5 in the Atmosphere at Seoul. J Korean Soc Atmos Environ. 2005;21(4):439-458.

5. Shin Moon-Khee, Lee Choong-Dae, Ha Hyun-Sup, Choe Choon-Suck, Kim Yong-Hee. The influence of meteorological factors on PM 10 concentration in Incheon. J Korean Soc Atmos Environ. 2007;23(3):322-331.

6. Eun-Jung Park, Misun Kang, Dae-Eun You, Dae-Seon Kim, Seung-Do Yu, Kyu-Hyuck Chung, et al. Health Risk Assessment of Heavy Metals in Fine Particles Collected in Seoul Metropolitan Area. Environ Health Toxicol. 2005;20(2):179-186.

7. OkheeYi, Yun-Chul Hong, Ho Kim. Seasonal effect of PM 10 concentrations on mortality and morbidity in Seoul, Korea: a temperature-matched case-crossover analysis. Environ Res. 2010;110(1):89-95.

8. Zanobetti A, Schwartz J. The effect of particulate air pollution on emergency admissions for myocardial infarction: a multicity case-crossover analysis., Environ Health Persp. 2005;113(8):978.

9. Oh KJ, Kwak J, Jung DY, Son GT. Statistical Analysis between Air Pollutants and Meteorological Factors in Pusan - Focusing at Kwanganli Area. J Korean Soc Environ Eng. 1998;20(9):1235-1245.

10. Kwon HJ, Cho SH. Air Pollution and daily Morality in Seoul. Korean J Prev Med. 1990;32(2).

11. Lee JT, Kim H. Epidemiology Methods and Study Desings for Investigating Adverse Health Effects of Ambient Air Pollution. Korean J Prev Med. 2001;34(2): 119-126.

12. Moon SW. Climate Change and Psychological Adaptation: Psychological Response, Adaptation, and Prevention. J Korean Soc Atmos Environ. 2016;32(3): 237-247.

13. Kim YU, Lee H, Jang YJ, Lee HJ. A Cluster Analysis on the Risk of Particulate Matter Focusing on Differences of Risk Perceptions and Risk-Related Behaviors based on Public Segmentation. J Public Relat. 2016;20(3): 201-235.

14. Ham JY, Lee HJ, Cha JW, R SB. Potential Source of PM10, PM2.5, and OC and EC in Seoul During Spring 2016. J Atmos Korean Meteor Soc. 2017;27(1): 41-54.

15. Hekap Kim, Kyung-Mi Jung, Tae-Sik Kim. Characteristics of Seasonal Distributions of Fine Particles (PM 2.5) and ParticleAssociated Polycyclic Aromatic Hydrocarbons inUrban, Metropolitan and Industrial Complex Sites. J Environ Toxicol. 1986;21(1):45-56.

16. Park Seung-Myung, Moon Kwang-Joo, Park Jong-Sung, Kim Hyun-Jae, Ahn Jun-Yong, Kim Jeong-Soo. Chemical characteristics of ambient aerosol during Asian Dusts and high PM episodes at Seoul intensive monitoring site in 2009. J Korean Soc Atmos Environ. 2012;28(3): 282-293.

17. Kang Choong-Min, Park Sung-Kyun, SunWoo Young, Kang Byung-Wook, Lee Hak-Sung. Respiratory health effects of fine particles (PM 2.5) in Seoul. J Korean Soc Atmos Environ. 2006;22(5): 554-563.

18. Hekap Kim, Kyung-Mi Jung, Tae-Sik Kim. Characteristics of Seasonal Distributions of Fine Particles (PM2.5) and ParticleAssociated Polycyclic Aromatic Hydrocarbons in Urban, Metropolitan and Industrial Complex Sites. Journal of Environmental Toxicology 2006;21(1):45-56.

19. Park Seung-Myung, Moon Kwang-Joo, Park Jong-Sung, Kim Hyun-Jae, Ahn Jun-Yong, Kim Jeong-Soo. Chemical Characteristics of Ambient Aerosol during Asian Dusts and High PM Episodes at Seoul Intensive Monitoring Site in 2009. J Korean Soc for Atmos Environ. 2012;28(3):282-293.

20. Jeon BI. Meteorological Characteristics of the Wintertime High PM10 Concentration Episodes in Busan. J Environ Sci Int. 2012;21(7):815-824. 